\title{
Versatile Grafts and Flaps in Reconstruction of Oral and Maxillofacial Postsurgical Defects
}

\author{
${ }^{1}$ Madhumati Singh, ${ }^{2}$ Anjan Shah, ${ }^{3}$ Shouvik Chowdhury \\ ${ }^{1}$ Professor and Head, Department of Oral and Maxillofacial Surgery, Raja Rajeswari Dental College and Hospital, Bengaluru, Karnataka, India \\ ${ }^{2}$ Reader, Department of Oral and Maxillofacial Surgery, Raja Rajeswari Dental College and Hospital, Bengaluru, Karnataka, India \\ ${ }^{3}$ Postgraduate Student, Department of Oral and Maxillofacial Surgery, Raja Rajeswari Dental College and Hospital, Bengaluru, Karnataka, India
}

Correspondence: Anjan Shah, Reader, Department of Oral and Maxillofacial Surgery, Raja Rajeswari Dental College and Hospital, Bengaluru, Karnataka, India, e-mail: nongha1@yahoo.co.uk

\section{ABSTRACT}

Ablative surgery for head and neck tumors is associated with significant disfigurement and loss of function. The main aim of the surgeon is to provide functional ability and esthetics of the patient. Type and extent of tissue loss from surgery relates to loss of soft tissue and bone. Reconstructions of jaw and mouth defects represent a challenge to the surgeon and are most commonly indicated in patients with oral squamous cell carcinoma. ${ }^{4}$ Primary closure and the restoration of form, cosmetics and function are the goals of reconstructive surgery. Various techniques have been practiced, including grafts, local flaps, regional flaps and free vascularized flaps even with diverse options, each one has its inherent advantages and shortcomings.

This article highlights our experiences with various reconstructive options, best possible reconstructive method to be followed to minimize morbidity of the patient.

Keywords: Postsurgical defects, Tumors, Reconstruction.

\section{INTRODUCTION}

Successful reconstruction after ablative surgery requires careful preoperative assessment and treatment plan. Important considerations include tumor stage and prognosis, patient age, sex and functional status, available reconstructive donor sites, and the psychosocial make-up of the patient. The aim of reconstruction is to maintain facial form, contour of the patient (i.e. esthetics) and functional ability (i.e. mastication and deglutition). ${ }^{4}$ All the above objectives are possible if proper reconstruction of bone and soft tissues are done.

\section{PATIENTS AND METHODS}

We have reviewed 12 cases, of which nine cases are reported as squamous cell carcinoma of oral cavity and a case of ameloblastoma, pleomorphic adenoma and ossifying fibroma, which has been reported to our department.

\section{Primary Closure (Figs 1 to 6 )}

A 48-year-old female patient reported to our department with squamous cell carcinoma of left lower gingivobuccal sulcus. The patient has undergone wide excision with modified radical neck dissection and primary closure is done. The advantages are greater availability of skin in elderly patients and quicker healing. The disadvantages are posttraumatic scar, esthetically patient is compromised.

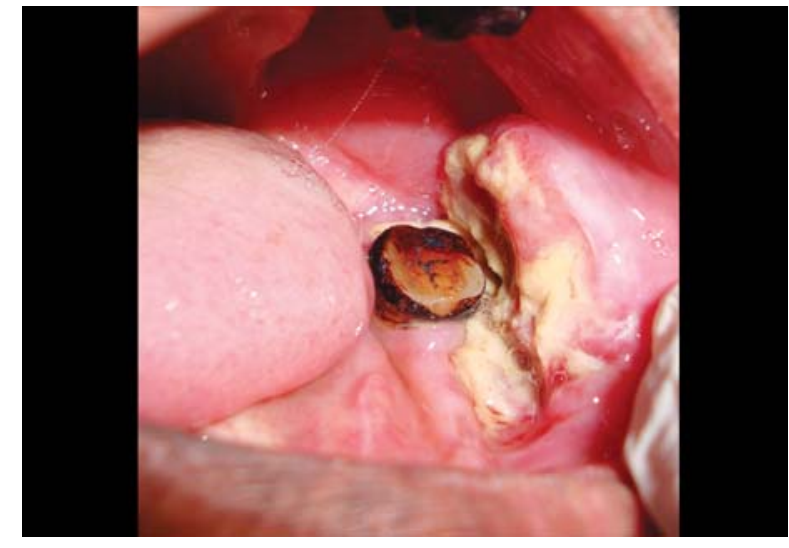

Fig. 1: Retromolar mandible and buccal carcinoma

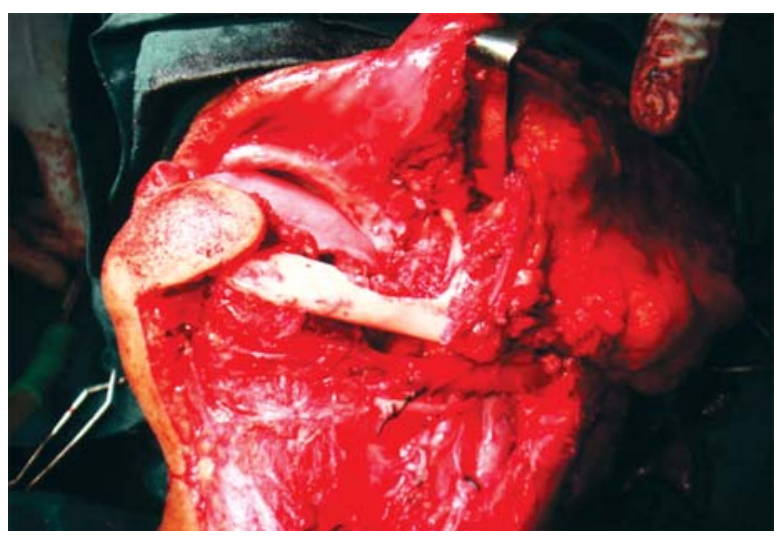

Fig. 2: Defect following marginal rim resection and neck dissection 


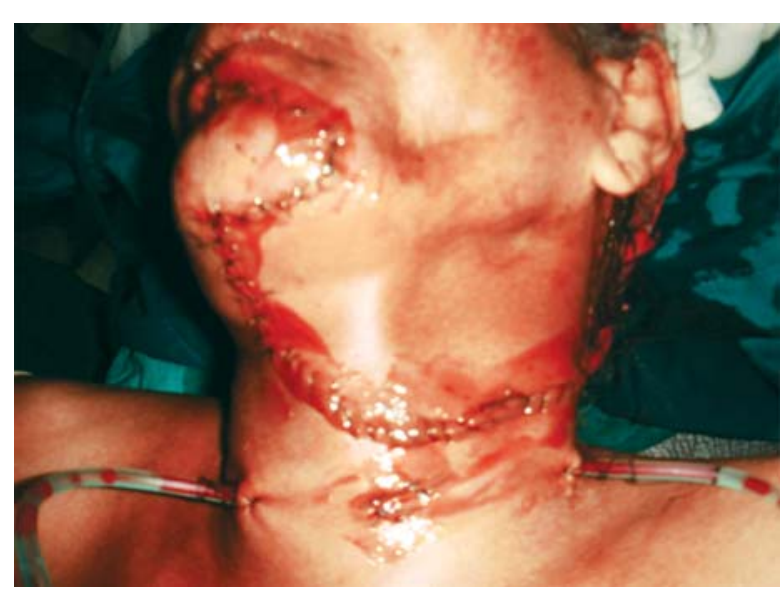

Fig. 3: Primary closure left buccal carcinoma defect

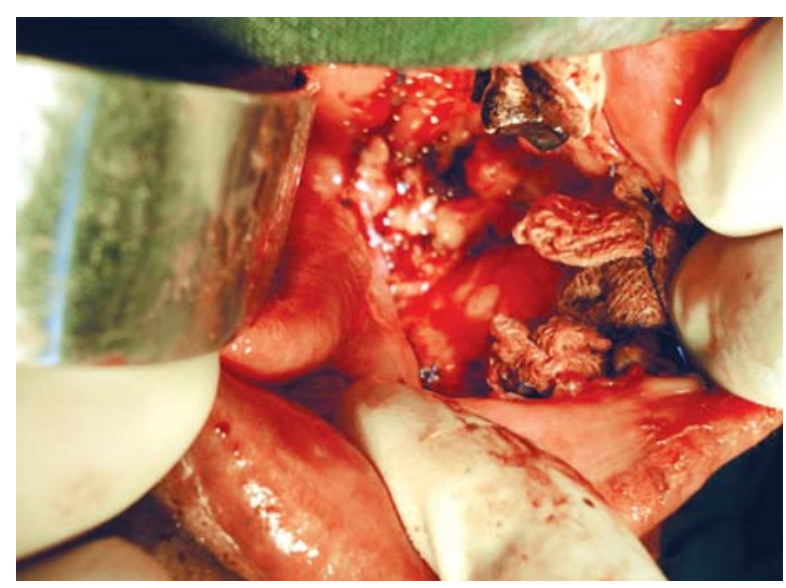

Fig. 4: Left buccal carcinoma intraoral resection defect

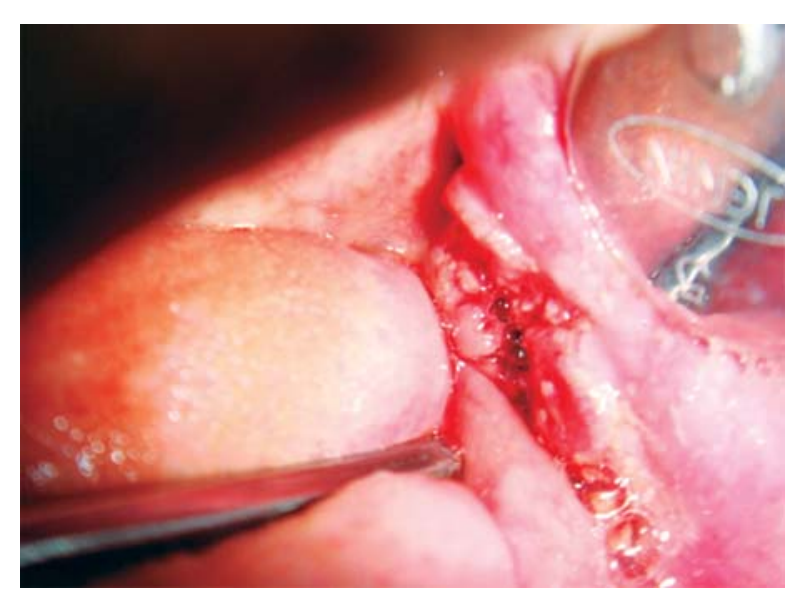

Fig. 5: Intraoral closure

\section{Split Thickness Skin Graft}

A 58-year-old female patient reported squamous cell carcinoma of right upper gingivobuccal sulcus (GBS) and has been reconstructed with split thickness skin graft. The

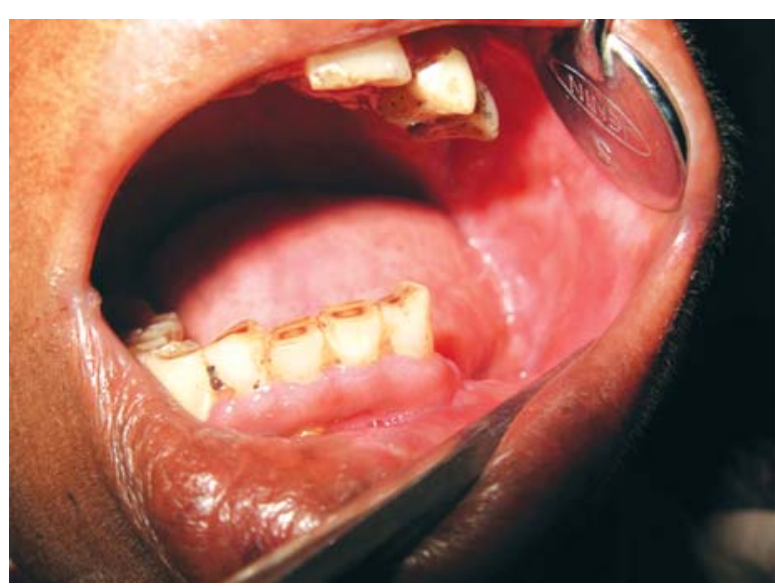

Fig. 6: Healed defect (1 month postoperative)

advantages are it can be taken under less favorable condition. The disadvantages are the graft shrinks considerably, chance of abnormal pigmentation, highly susceptible to trauma and chance of formation of fistula.

\section{Buccal Fat Pad}

A 45-year-old female patient with squamous cell carcinoma of left lower GBS reported to our department. She has undergone wide excision along with supraomohyoid neck dissection. The advantages of buccal fat pad are rapid reepithelialization, rich vascular supply, less donor site skin scars. Disadvantages are it is prone to dehiscence.

\section{Nasolabial Flap (Figs 7 to 10)}

A 56-year-old female patient reported to our department with squamous cell carcinoma of left lower anterior alveolus. In this case, marginal mandibulectomy (MRND) has been done and reconstruction is done with nasolabial flap. The advantages of this flap are large amount of tissue and good cosmetic result following closure of the donor site. The disadvantages are hair growth from the flap in patients who do not receive radiotherapy and the flap pedicle must crossover the occlusal table of dentate patients.

\section{Sternocleidomastoid Flap (Figs 11 to 17)}

A 56-year-old male patient reported to our department with squamous cell carcinoma of right lower GBS. The patients underwent wide excision with marginal mandibulectomy and reconstruction is done with sternocleidomastoid muscle flap. The advantages are proximity of recipient site, one stage procedure, total flap loss is rare, good color match, sufficient bulk.

\section{Pectoralis Major Myocutaneous Flap (Figs 18 to 20)}

It is known as Work Horse of reconstruction.

Three cases of squamous cell carcinoma have been operated in our institution and reconstruction is done with 


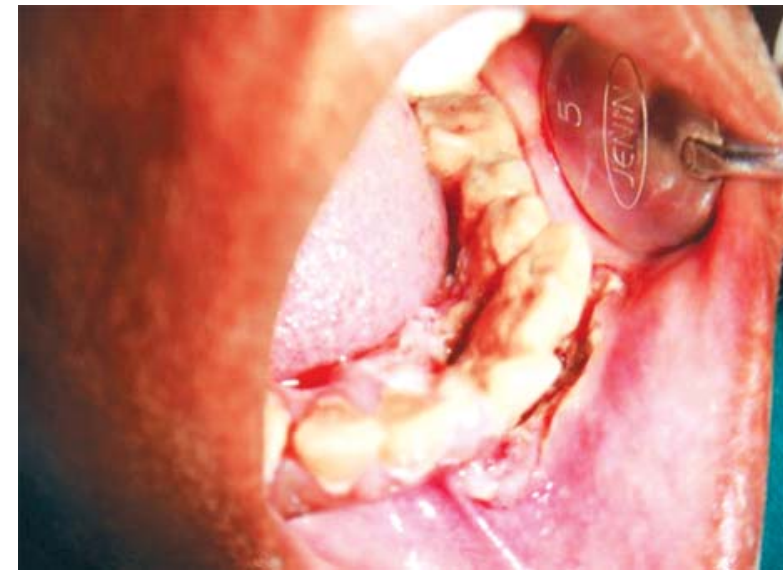

Fig. 7: Anterior mandibular alveolar carcinoma

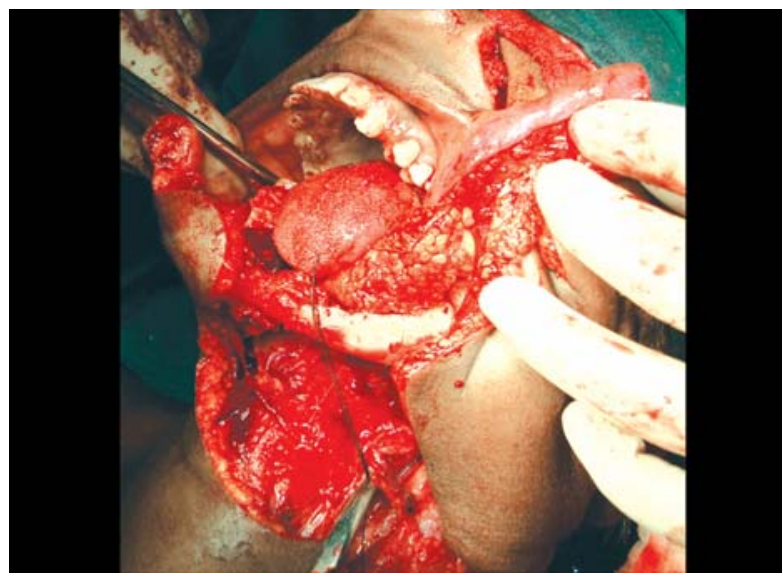

Fig. 8: Defect following resection of mandibular alveolar carcinoma

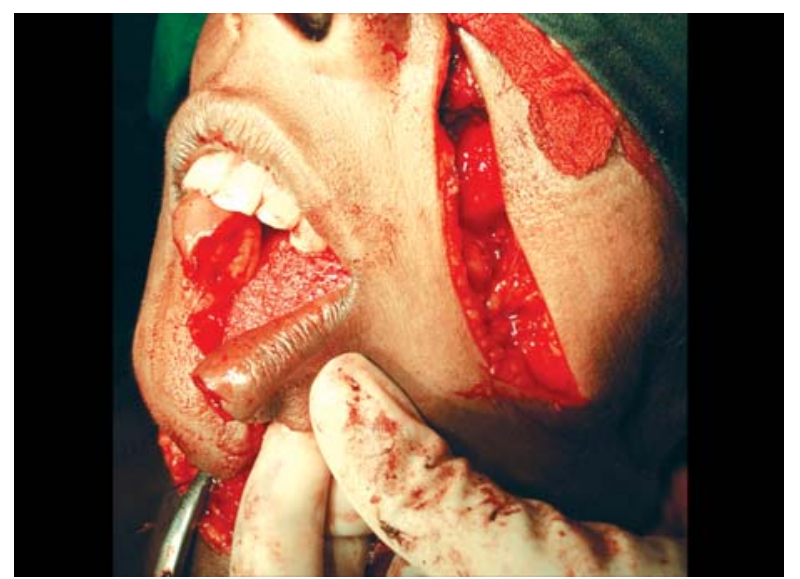

Fig. 9: Nasolabial flap rotated into oral defect

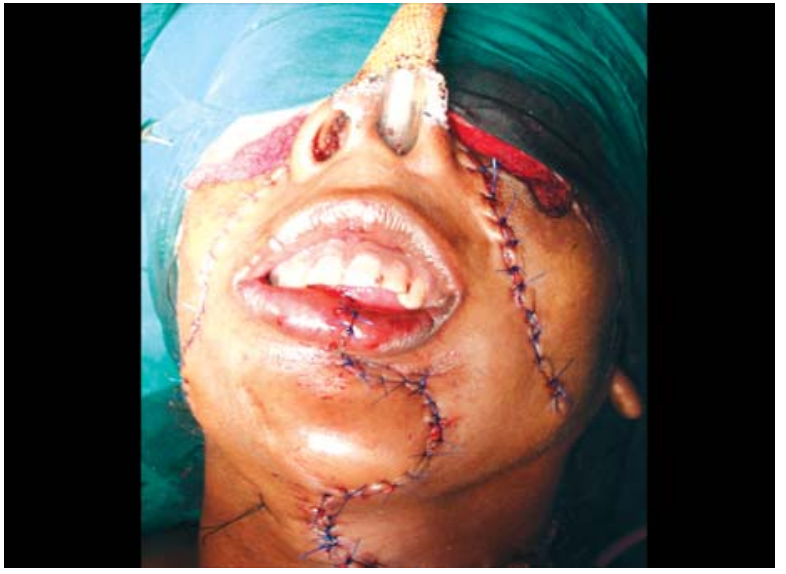

Fig. 10: Closure following nasolabial flap reconstruction

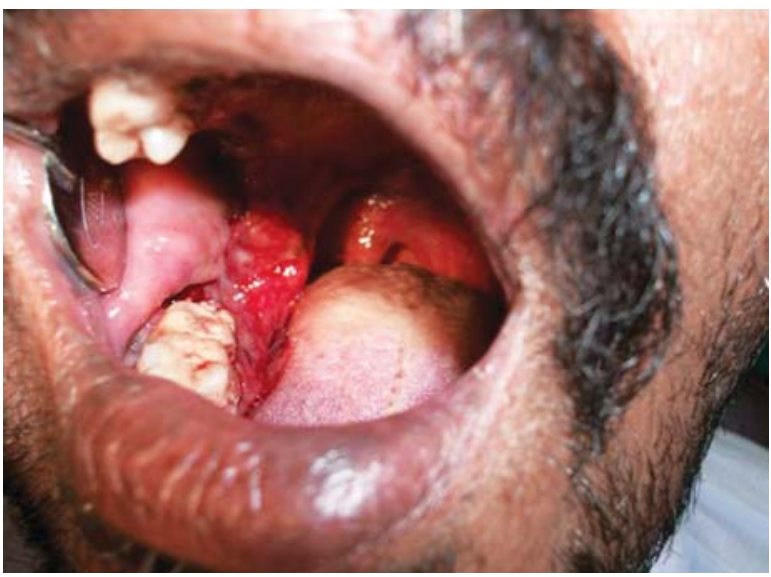

Fig. 11: Retromolar carcinoma

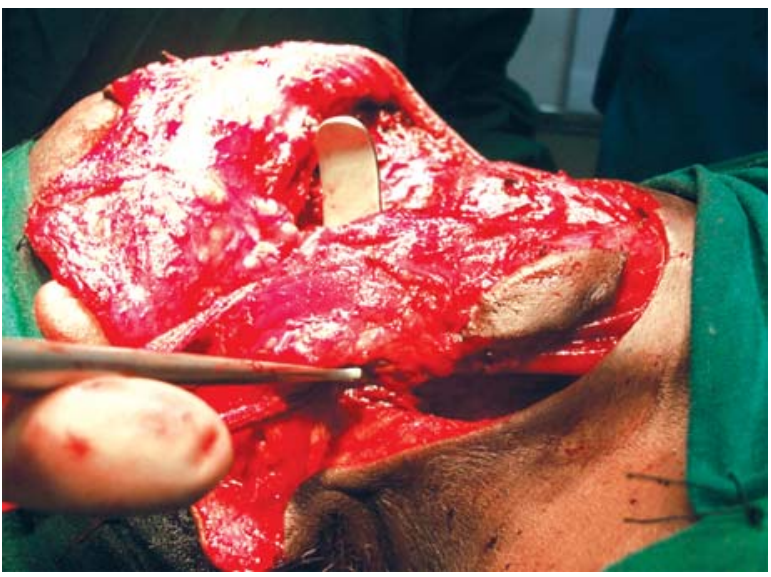

Fig. 12: Sternomastoid flap with skin island pectoralis major myocutaneous flap. The advantages are it provides generous portion of skin, soft tissues, muscle and bone, has consistent blood supply, arc of rotation is more than $20 \mathrm{~cm}$, it has sufficient bulk, good functional/cosmetic results, donor site can be closed primarily and it provides hairless area. The disadvantages are the flap is too bulky, 


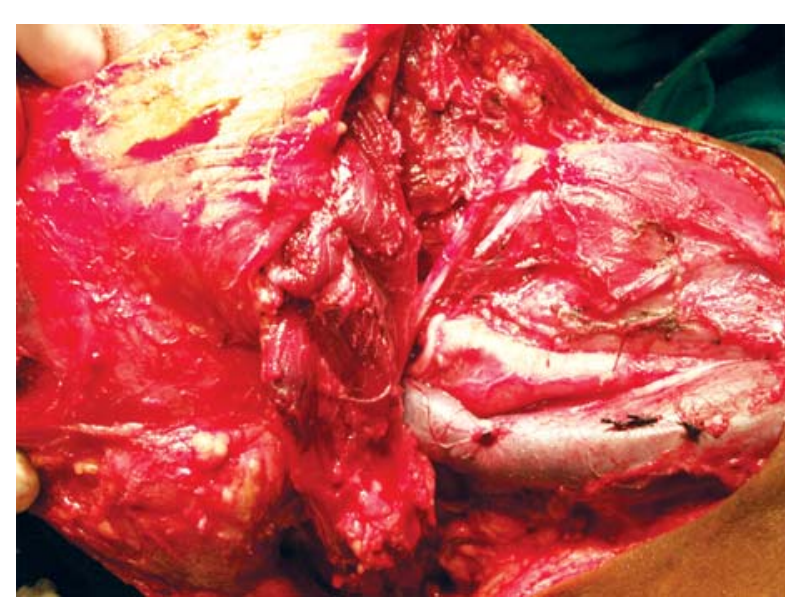

Fig. 13: Sternomastoid flap rotated into oral defect

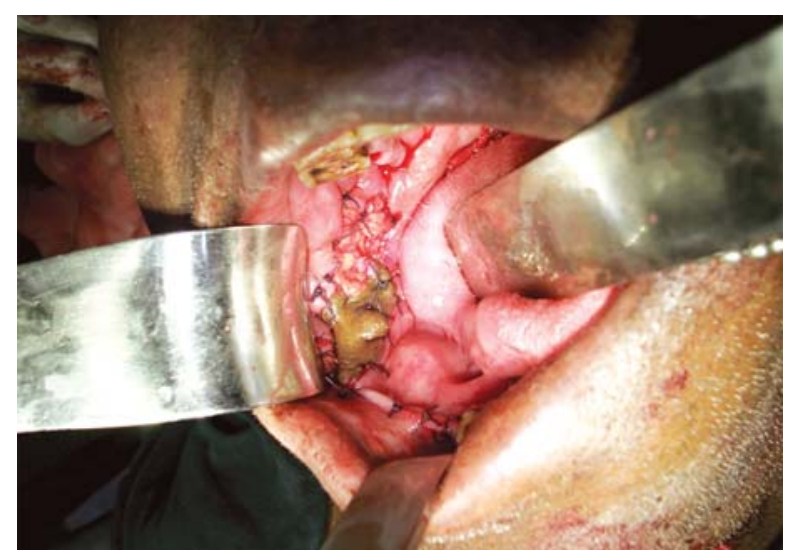

Fig. 14: Intraoral view of inset sternomastoid flap

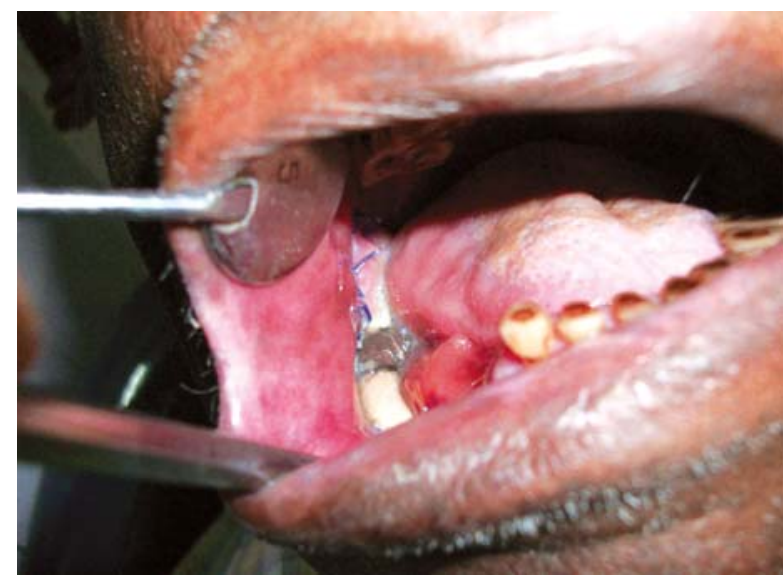

Fig. 15: Four weeks postoperative view of sternomastoid flap reconstruction

loss of muscle noticeable is male, distortion of symmetry in females, difficulty to identify the vascular pedicle.

\section{Fibula Free Flap (Figs 21 to 23)}

A 39-year-old male patient reported to our department with a swelling in lower anterior mandibular region. The patient

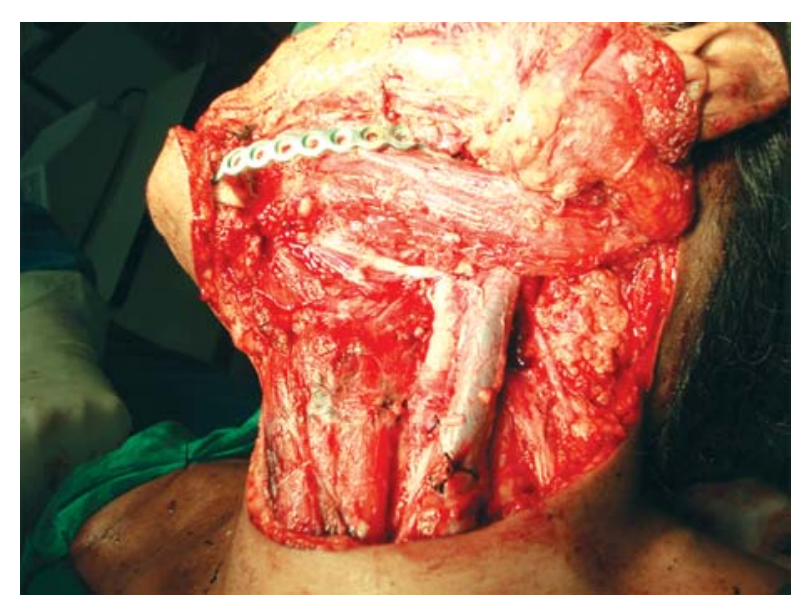

Fig. 16: Sternomastoid flap to cover reconstruction plate

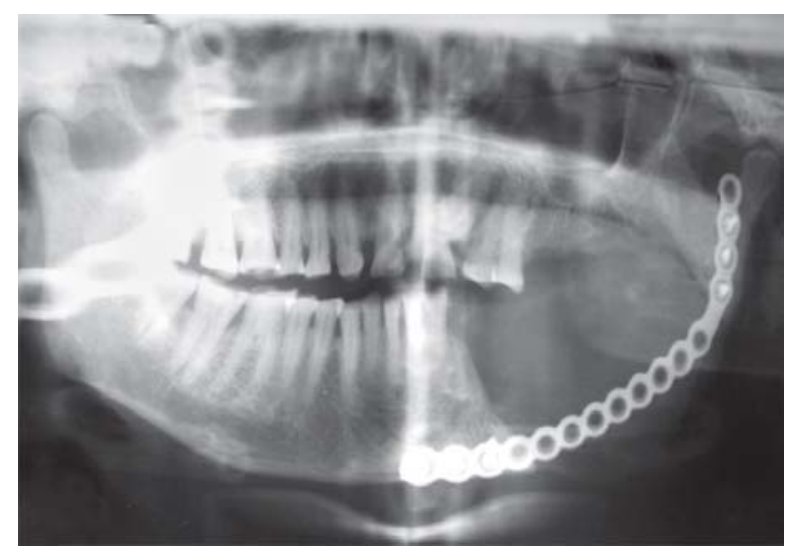

Fig. 17: OPG of recostruction plate following segmental resection

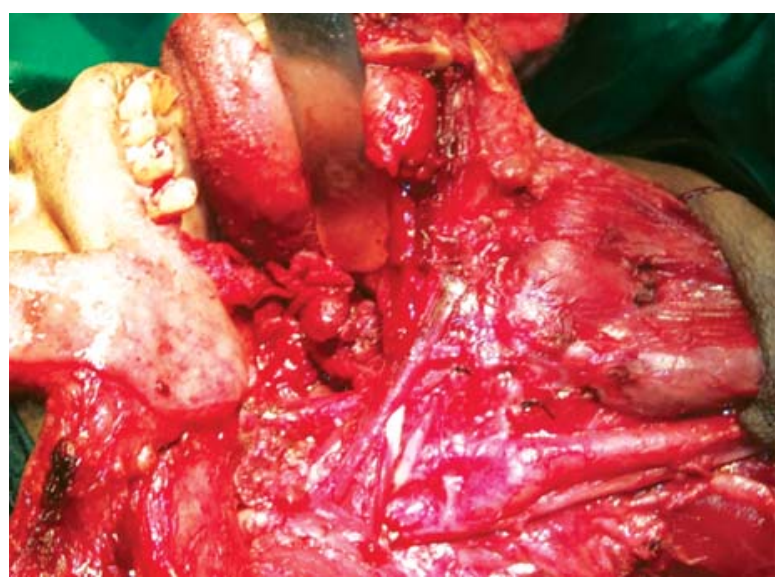

Fig. 18: Mandible carcinoma-segmental resection and neck dissection defect

has been diagnosed as ameloblastoma after routine investigations and radiographs. Resection of ameloblastoma is done and reconstruction is done with fibula free flap. The advantages are uniform width and length $(20-25 \mathrm{~cm}) .^{5}$ It has ability to incorporate skin or muscle component with the flap. Disadvantage are chance of flap loss by thrombosis. 


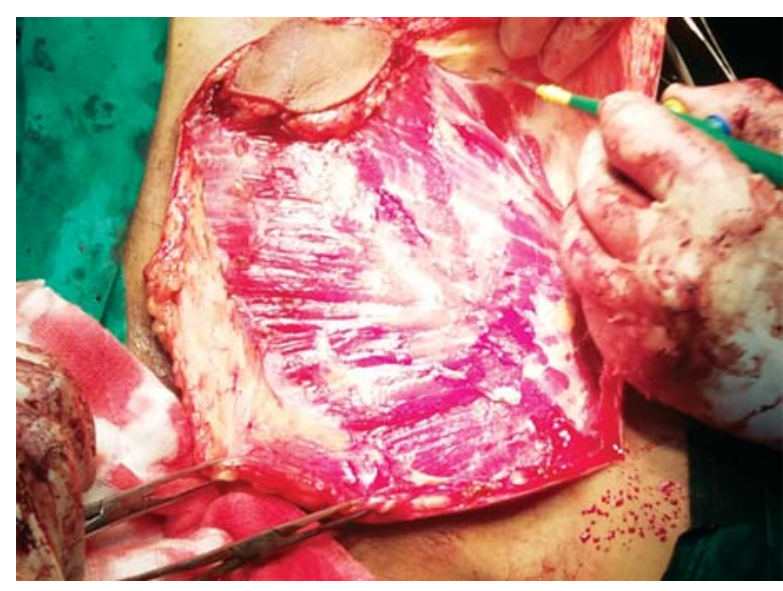

Fig. 19: Pectoralis major pedicled flap raised

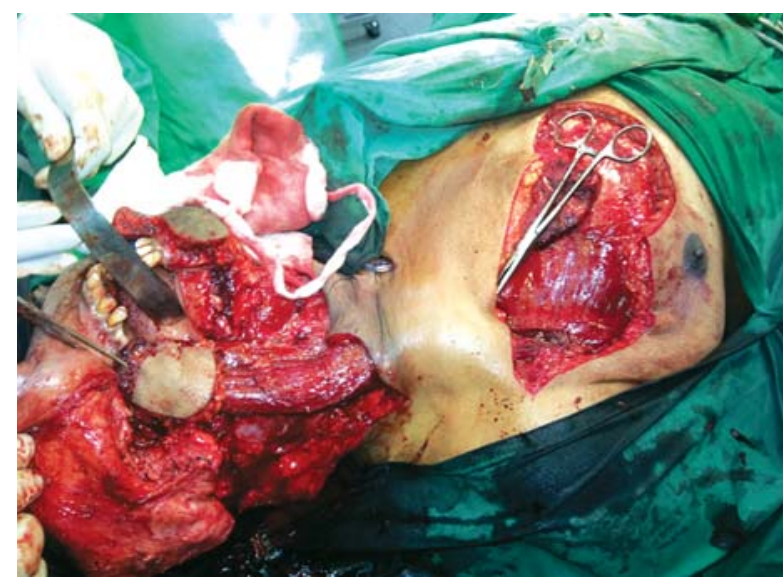

Fig. 20: Pectoralis major flap rotated into defect

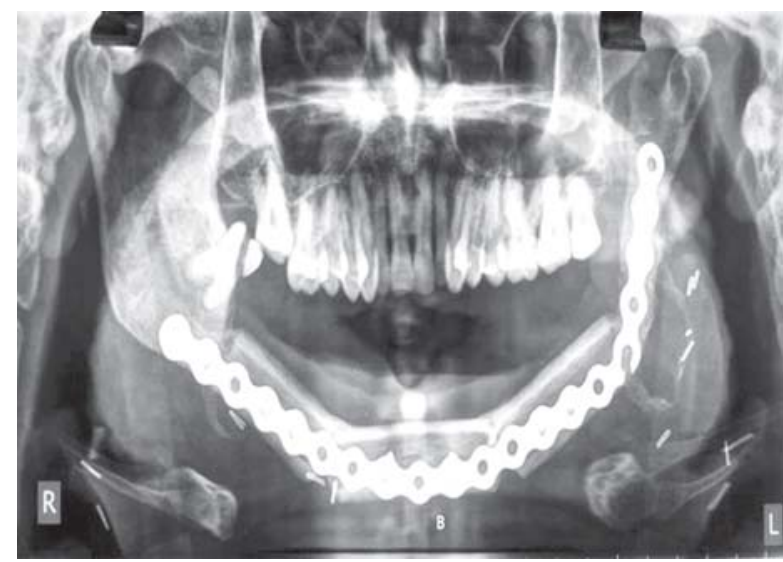

Fig. 21: OPG of mandible reconstructed with fibula flap

\section{Iliac Crest Free Flap}

A 18-year-old female patient reported to our department with swelling of right lower face region. OPG reveals welldefined radioluscency on right body of mandible. Biopsy suggests ossifying fibroma. In this case, segmental

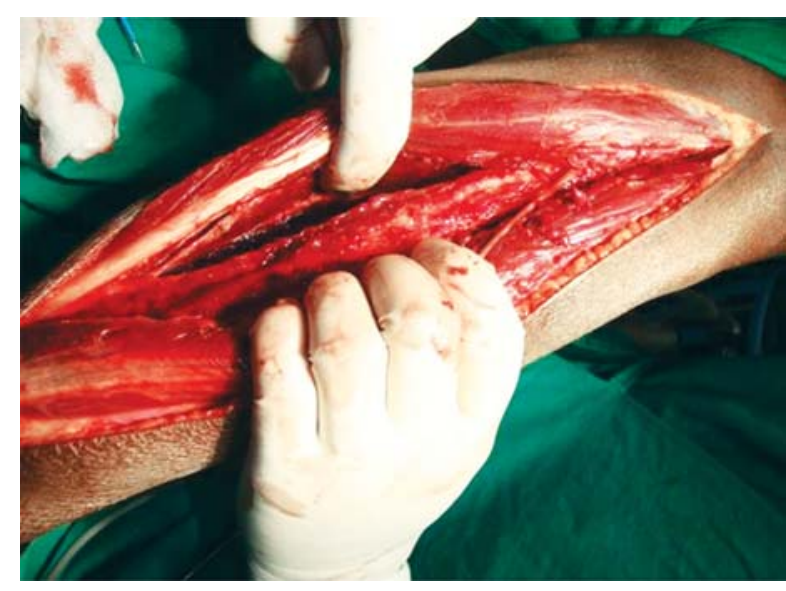

Fig. 22: Fibula flap raised

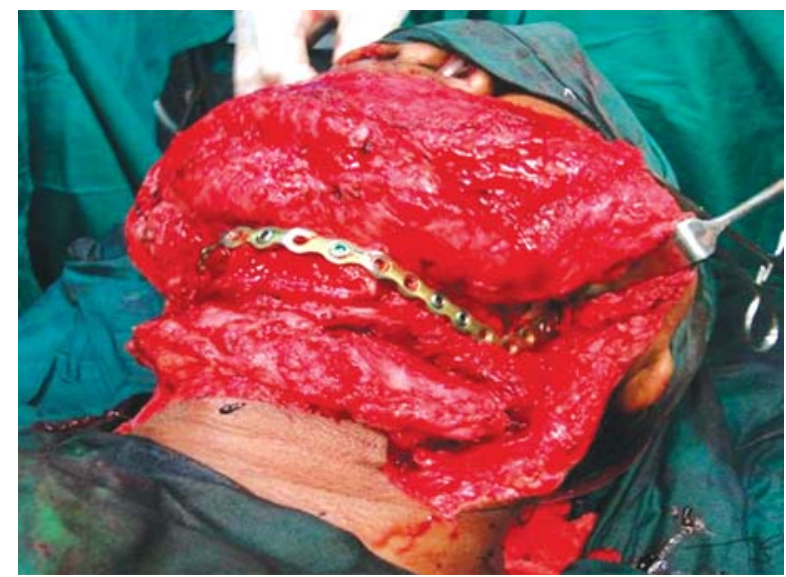

Fig. 23: Fibula flap osteotomized and fixed to residual mandible

mandibulectomy (SND) is done and reconstruction done with iliac crest free flap. The advantages are only vascularized bone used extensively with simultaneous or delayed endosteal dental implant placement. Disadvantages are perforation of abdominal viscus, herniation of intraabdominal contents.

\section{Temporalis Myocutaneous Flap}

A 26-year-old male reported to our department with a swelling of left palate. FNAC confirms pleomorphic adenoma of hard palate. Excision is done and reconstruction done with temporalis myocutaneous flap. The advantages are it is highly vascular, pliable and durable. The disadvantages are frontal branch weakness of facial nerve as the nerve travels in temporoparietal fascia. Secondary alopecia due to damage of hair follicles for superficial dissection.

\section{Radial Forearm Flap (Figs 24 and 25)}

A 45-year-old male patient reported to our department with squamous cell carcinoma of lower gingivobuccal sulcus 


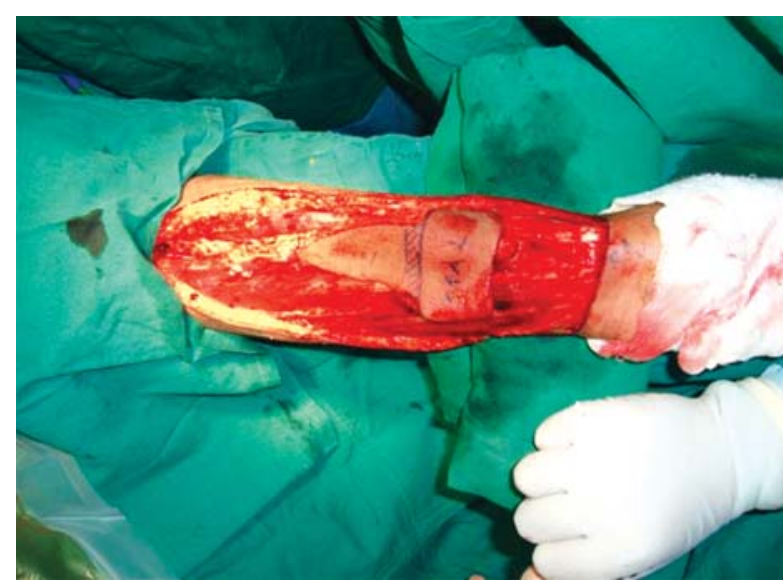

Fig. 24: Bipaddled radial forearm flap raised

near the angle of mouth which perforates through the skin. In this case, modified radical neck dissection is done along with wide excision and the defect is reconstructed with radial forearm flap. The advantages of this flap are its versatility, long pedicle $(12-15 \mathrm{~cm})$, easy to raise, reliable, thin pliable and often hairless skin. ${ }^{6}$ The disadvantages are donor site defects are visible and usually needs skin graft for the defect.

\section{DISCUSSION}

Mathes in 1982 was the first person to describe a systematic approach in reconstruction of head and neck. However, his description of reconstruction ladder was focused towards

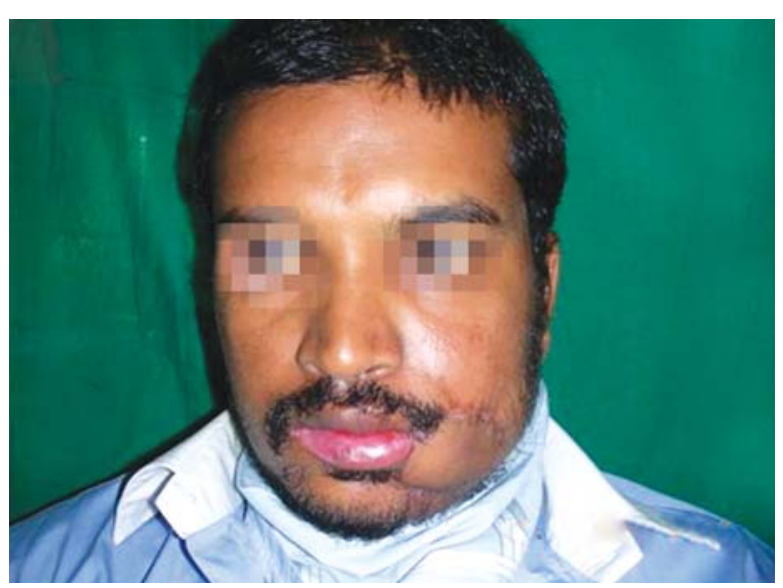

Fig. 25: Reconstruction of extensive buccal carcinoma defect with bipaddled radial forearm

closure of the defect. There was no consideration for esthetics and function. With the evolution of reconstructive techniques and the focus of life in cancer treatment, the esthetic and functional outcome has become an important criteria in selecting a reconstruction (Table 1). At present, pectoralis major myocutaneous flap described by Aryan (1978) is still the "Work Horse" for most head and neck reconstruction. ${ }^{1}$ However, free flap reconstruction is becoming more popular and available. Kroll et al (1997) demonstrated that the morbidity for free flaps reconstruction was lower than pectoralis major myocutaneous flap resulting in shorter hospital stay and cost benefits. ${ }^{2}$

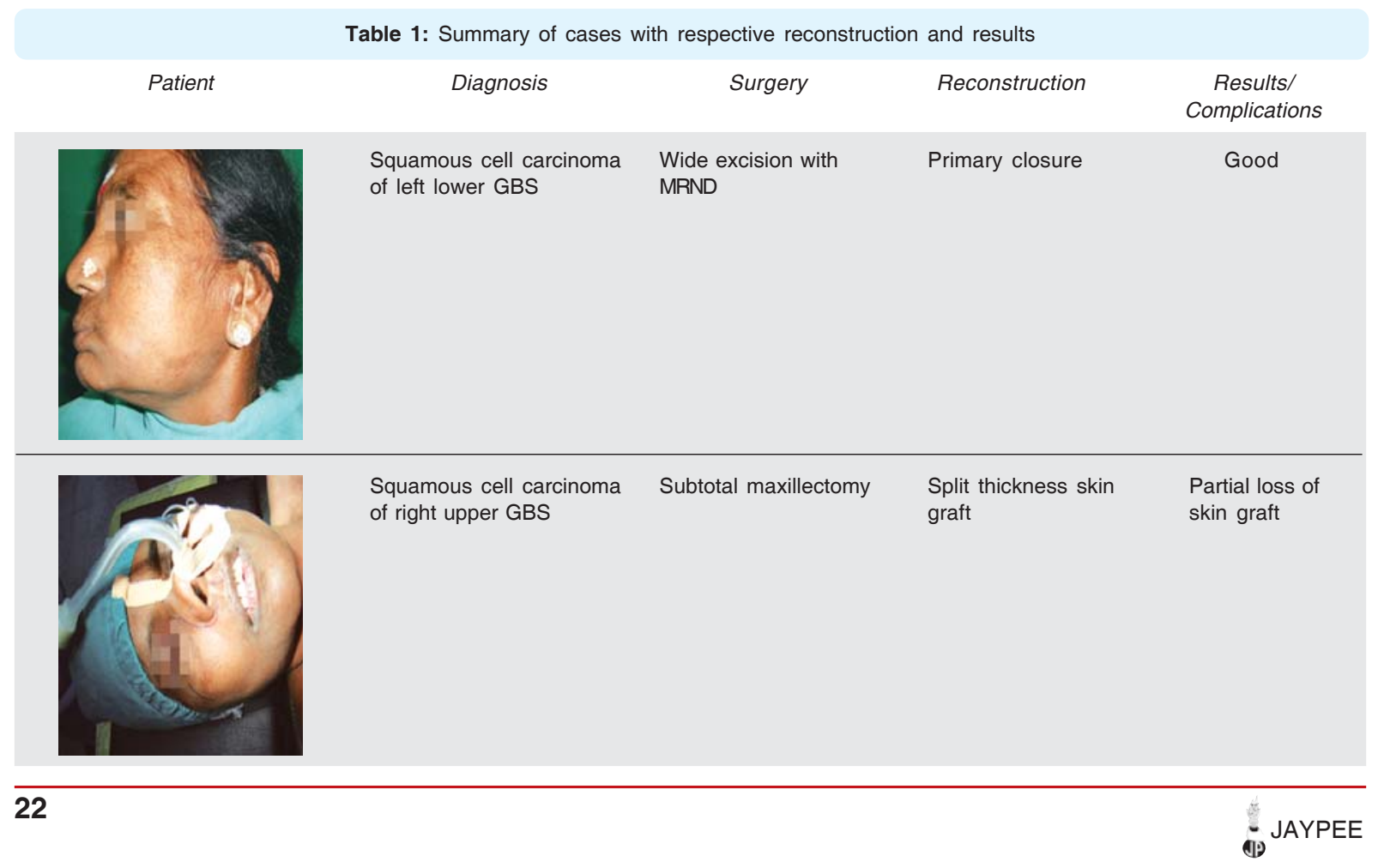


Versatile Grafts and Flaps in Reconstruction of Oral and Maxillofacial Postsurgical Defects

contd...

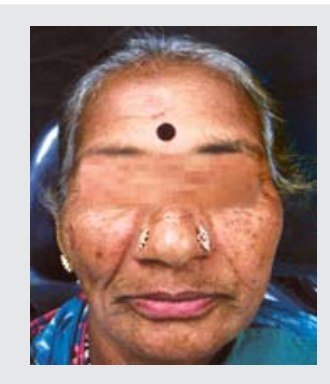

Squamous cell carcinoma

of left lower GBS

Wide excision with

Buccal fat pad

Good

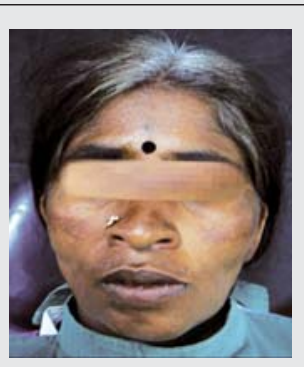

Wide excision and

Nasolabial flap

Good

Squamous cell carcinoma

en bloc resection with

MRND

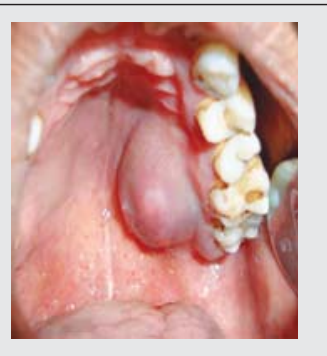

Pleomorphic adenoma

Excision/maxillectomy

Tempo

Oronasal fistula

which closed

spontaneously with

healing plate

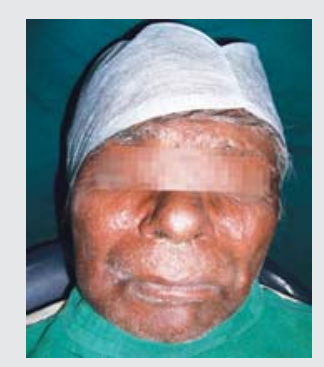

Wide excision +

Sternocleidomastoid

Good

Squamous cell

carcinoma of right lower

marginal

muscle flap

mandibulectomy with

MRND

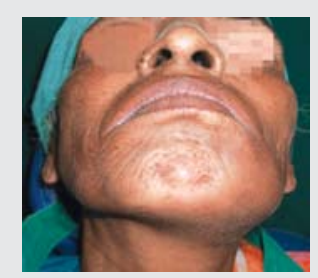

Squamous cell

carcinoma of left

lower GBS

Segmental

mandibulectomy with

selective neck

dissection

Self locking titanium

Good

plates +

sternocleido-

mastoid muscle

flap

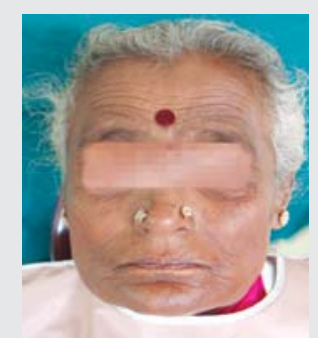

Hemimandibulectomy

with functional neck

Pectoralis major

dissection

Neck fistula

requiring

secondary

lower GBS

myocutaeous flap

revision

Contd... 
contd...

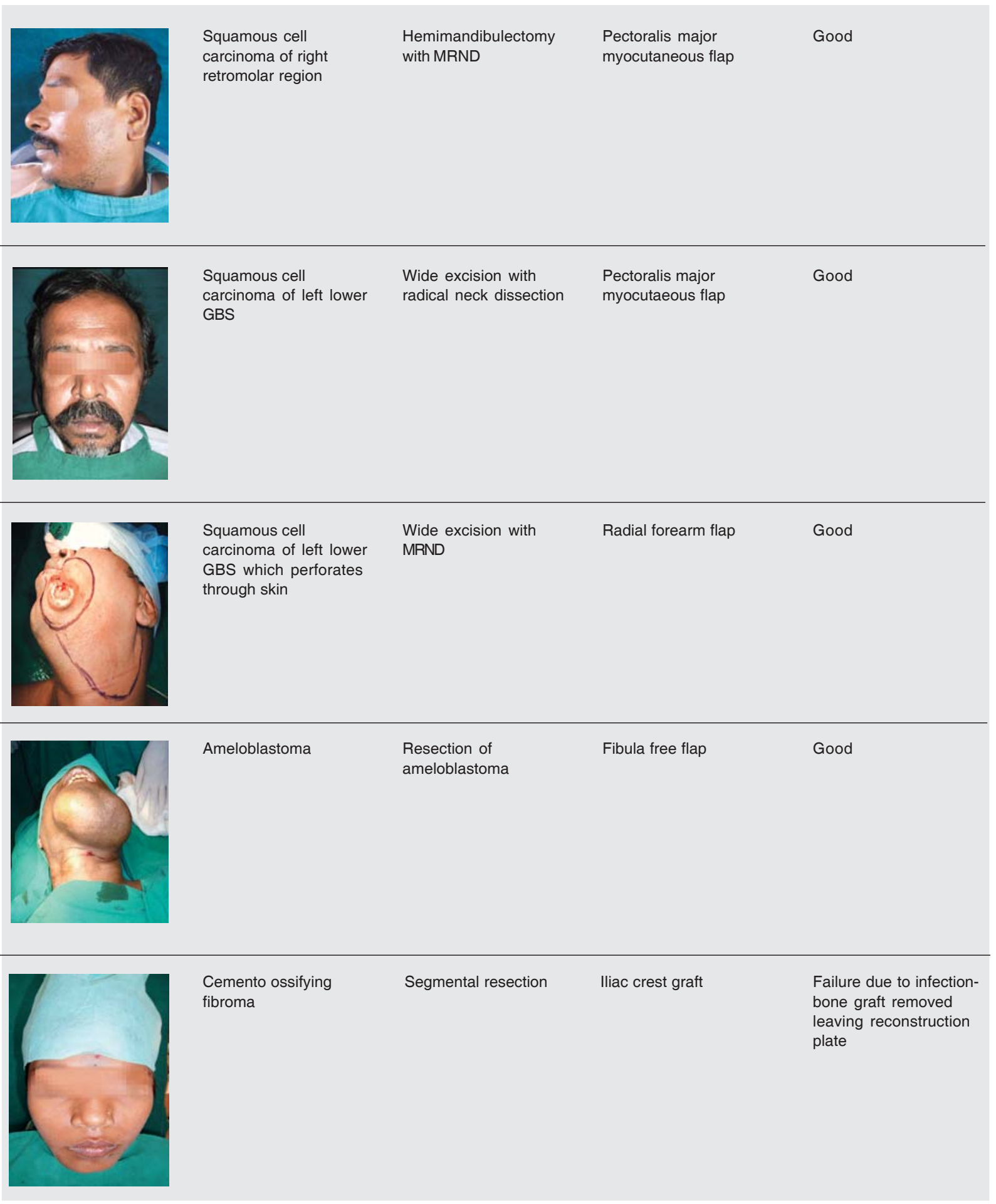

Pompeis (1998) also showed the functional superiority of radial forearm flap over pectoralis major myocutaneous flap. ${ }^{3}$ Particularly in mandibular reconstruction, the vascularized fibula has shown to be far superior to free corticocancellous bone, specially when postoperative radiotherapy is necessary.

In our experience, depending on the size of defect and patient's functional needs, the whole range of reconstructive 
options can be used reliably. However, the split thickness skin grafts and free corticocancellous bone had a lower success than others.

\section{CONCLUSION}

Head and neck reconstruction is an extremely demanding process that needs continuous improvements and refinements. Methods available in reconstructing defects depends on size of the defect, patient's compliance, anatomical and pathological factors. Versatile methods available for reconstruction-starting from grafts, local flaps to microvascular flaps which enhance the quality of life of the patient.
Introduction of microvascular free flap reconstruction (1959) enhances the function and esthetics of patient. Evolution of technique and technology enhanced the reliability of free tissue transfer and it has become a valuable tool for reconstruction. In recent years, free flaps have become the work horse in head and neck reconstruction.

\section{REFERENCES}

1. Oral Maxillofacial Surg Clin N Am 15 2003;565-75.

2. Plastic and Reconstructive Surg 1997;99(5).

3. Minerva Chirurgica 1998;53(3).

4. Oral Cancer: Dr Jatin p Shah 299-32.

5. Head and Neck Surgery: Stell and Maran 106-07.

6. Operative Maxillofacial Surgery: Langdon 83-87.

7. Maxillofacial Surgery(Vol I ): Peter Ward Booth 570-77. 